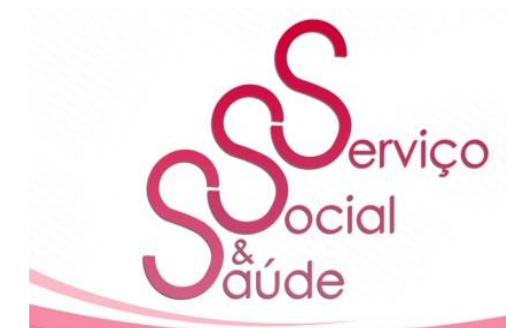

ISSN 2446-5992

(๑⿻)

10.20396/sSS.v19i0.8665482

EDITORIAL

\title{
Tempo, História, Saúde e Defesa da Vida
}

\section{Edna Maria Goulart Joazeiro}

\section{Editora Cientifica Serviço Social \& Saúde}

$\boldsymbol{U}_{\mathrm{m}}$ periódico tem como desafio histórico acompanhar as múltiplas formas de manifestação da história do presente, mas deve fazê-lo, sem perder de vista, a historicidade destas construções societais, culturais e temporais. A expressão "tempo" remete a uma relação de posição ou de segmentos de sequências de acontecimentos em evolução contínua, diria Elias (1998, p. 13), contudo, diríamos nós, que estes acontecimentos fazem parte de um denso movimento entre o que foi, entre o que é e o que há de ser.

Nesse diálogo entre passado, presente e futuro, recorro à metáfora da viagem de Ianni (2003, p. 13), na qual afirma que "toda viagem se destina a ultrapassar fronteiras, tanto dissolvendo-as como recriando-as. Ao mesmo tempo que demarca diferenças, singularidades ou alteridades, demarca semelhanças, continuidades, ressonâncias”.

O tempo, segundo Elias (1998), é uma representação simbólica de uma vasta rede de relações, é antes de tudo um símbolo social, resultado de um longo processo de maturação, pois nele está condensado o caráter de dimensão universal assumido pelo tempo, uma vez que essa dimensão "é apenas uma figuração simbólica do fato de que tudo o que existe encontrase no fluxo incessante dos acontecimentos" (ELIAS, 1988, p. 31).

Um olhar atento para a história da humanidade revela, que "os problemas que os homens procuram resolver, ao medirem a 'duração' do tempo remete ao fato de que os grupos humanos estão situados no interior de um conjunto mais vasto do que o formado por eles" (op. cit, p. 31) próprios. A travessia que a humanidade ora empreende, nesse difícil momento da história no enfrentamento dos agravos a saúde decorrentes da pandemia da COVID-19, 


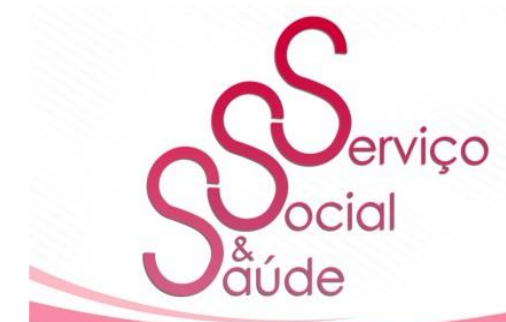

ISSN 2446-5992

(๑⿻)

10.20396/sss.v19i0.8665482

impõe sérios obstáculos aos sistemas de saúde, ao mesmo tempo, que expõe limites relativos à ampliação da desigualdade social, revelando de modo inelutável as diferenças no acesso a proteção de si em face das condições objetivas do viver e do sobreviver de grandes contingentes da população nos nossos muitos Brasis.

No ano de ano de 2020, nos encontramos com um desafio histórico, a emergência de uma nova doença, a pandemia decorrente do novo coronavírus desencadeou um contexto de elevada incerteza quanto à capacidade do Estado e dos Sistemas de Saúde de responderem de forma pertinente ao enfrentamento desse agravo à saúde, tanto da dimensão sanitária, quanto econômica, política e social da pandemia.

A combinação da crise estrutural do capital, com os efeitos adversos da pandemia tem exigido dos Estados Nacionais a adoção de ações imediatas por parte dos governos. As autoridades sanitárias internacionais e um amplo conjunto de governos nacionais têm de diferentes formas, combinado três grandes estratégias, são elas, i) recomendação ou determinação de isolamento e de distanciamento social; ii) a ampliação da capacidade de atendimento dos serviços de saúde; iii) formas de apoio econômico a cidadãos, famílias e empresas (PIRES, 2020, p. 7). E, após o desenvolvimento de vacinas, uma outra estratégia passou a ser requerida, o planejamento combinado das estratégias anteriores com a oferta de vacinas às populações concernidas, fazendo-o em consonância com o compromisso e a responsabilidade de cada governo nacional.

No Brasil, diante do cenário da pandemia da COVID-19, as quatro estratégias de intervenção supramencionadas têm ocorrido mediante ações e medidas isoladas, por parte de diferentes níveis de governo, sem um esforço claro de articulação e coordenação em nível nacional para o enfrentamento da crise (PIRES, 2020, p. 7) sanitária e humanitária.

Em face da multiplicidade de dimensões que está presente no contexto dessa crise, torna-se necessário que Estado, Ciência, Universidade, Sistema de Saúde, Políticas Sociais e Sociedade se articulem buscando cada qual investigar dentro da concepção da totalidade concreta, de forma a explicitar, as múltiplas determinações e mediações históricas que constituem esse tempo. Chesnais (2013) ao analisar os desafios para o enfrentamento da crise 


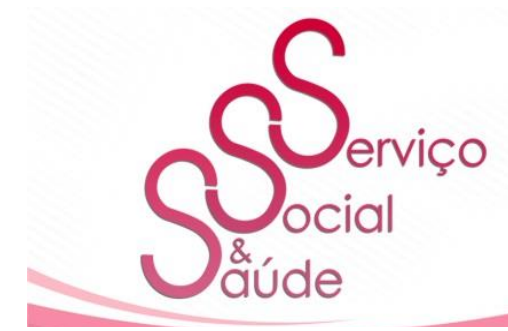

ISSN 2446-5992

(๑⿻)

10.20396/sss.v19i0.8665482

mundial de nosso tempo, afirma que "no século XVI, os navegadores ingleses forjaram a bela expressão 'uncharted waters': águas inexploradas, para as quais inexiste carta marítima”. Segundo o autor, vivemos hoje essa situação, pois não dispomos de conhecimento para enfrentar as complexidades presentes na atualidade. Conforme assinala Frigoto (2008), a historicidade dos fatos sociais consiste fundamentalmente na explicitação da multiplicidade de determinações fundamentais e secundárias que os produzem.

Estamos diante de um imperativo ético e epistemológico, de empreender um esforço "mais aprofundado de conhecimento dos seus movimentos, tendências, contratendências e relações, com vista ao estabelecimento de estratégias de políticas dialeticamente interligadas" (PEREIRA, 2014, p. 24).

As políticas sociais são atravessadas por contradições e conflitos, produto de interesses antagônicos e que pressupõe a compreensão das múltiplas dimensões da crise, ao mesmo tempo, que requer a necessidade de uma leitura na perspectiva da totalidade. A respeito da relação que se tece entre história e memória, cumpre assinalar a riqueza de perspectiva que se abre quando os conceitos são desdobrados em favor de uma apreensão da multiplicidade de dimensões que estão presentes, nesse difícil momento da história do Brasil, do SUS e do Sistema de proteção social, historicamente construídos.

Nesse sentido, o contexto de pandemia causado pela COVID-19 tem requisitado das diversas instâncias, dentre elas, da universidade pública, de periódicos científicos, construir espaços dialógicos e formativos capazes de ampliar a compreensão dos efeitos da COVID-19, dos cuidados à saúde viabilizando o conhecimento da dinâmica instaurada no período de pandemia, criando ainda espaços de reflexão sobre o uso de tecnologias de intervenção e de monitoramento do trabalho profissional visando ampliar o conhecimento sobre esse agravo a saúde, o uso de Equipamentos de Proteção Individual (EPI) e a ampliada necessidade de rediscussão de protocolos de atenção e da instrumentalidade requerida pelo e no atual cenário pandêmico, além da indiscutível necessidade de sensibilizar governantes, gestores, trabalhadores da saúde e das demais políticas sociais e as populações concernidas sobre as ameaças à vida presentes no atual momento da história. 


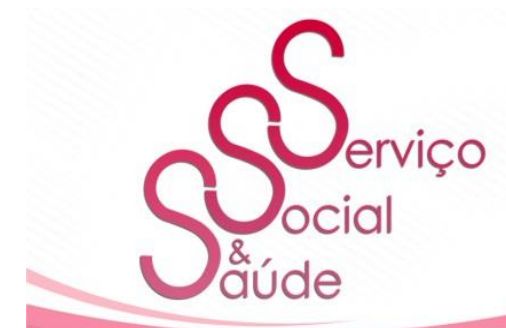

ISSN 2446-5992

(๑⿻)

10.20396/sSS.v19i0.8665482

O Conselho Editorial e o Conselho Científico do periódico Serviço Social \& Saúde apresentam à Comunidade Científica e aos leitores o exemplar do décimo nono ano de existência e de publicação ininterrupta da Revista. O exemplar foi organizado com base nas discussões nascidas no campo da Saúde, que se ampliam para análises e debates transversais às demais políticas sociais diante da necessidade de enfrentamento das desigualdades sociais no acesso ao direito em presença do subfinanciamento das políticas públicas e da redução de sua dimensão universal.

Na abertura do exemplar, no artigo denominado A demanda no processo de trabalho dos assistentes sociais e sua configuração em serviços de saúde de autoria de Francielle Lopes Alves e de Regina Célia Tamaso Mioto, bem como no artigo Processos de trabalho coletivo em saúde e o trabalho do/a assistente social: os fios (in)visíveis que materializam o conceito ampliado de saúde de autoria de Anderson da Silva Fagundes e Dolores Sanches Wünsch e no artigo Estresse ocupacional e os impactos na saúde das assistentes sociais de uma Unidade Hospitalar de atendimento à criança em Boa Vista - Roraima de autoria de Tatianne Lorenna Vieira Medeiros, Kesy Stheffany Silva Lopes e Janaine Voltolini de Oliveira cujas análises empreendidas pelos autores nos convidam a refletir sobre as relevantes questões que envolvem a atenção à saúde e a produção do cuidado em tempos de ampliação da desigualdade social e de crise sanitária.

No que tange a questão da dimensão gestionária do trabalho, as autoras Priscilla Fernandes Fagundes, Estela Márcia Rondina Scandola e Keila Regina de Oliveira no artigo Gestão de alta hospitalar em Cuidados Continuados Integrados (CCI), apresentam o Programa cujo objetivo é atender pessoa que apresenta dependência funcional potencialmente susceptível de recuperação, por meio de uma abordagem integral que contemple as necessidades físicas, psíquicas, emocionais e sociais.

Nesse exemplar tivemos a honra de apresentar uma densa contribuição sobre os Desafíos para la Salud Mental en tiempos de crisis de autoria do Professor Benedetto Saraceno ilustre pesquisador, médico psiquiatra, psicofarmacologista e sanitarista que 


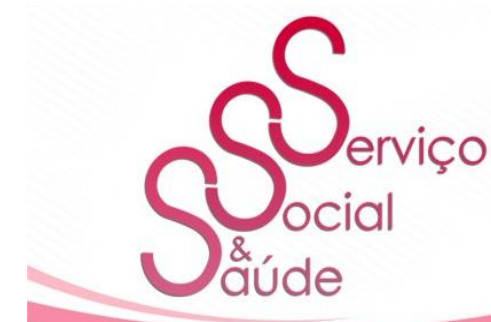

ISSN 2446-5992

(๑⿻)

10.20396/sss.v19i0.8665482

trabalhou com Franco Basaglia. Atualmente é Secretário Geral do Lisbon Institute of Global Mental Health, CEDOC da New Medical School de Genebra, Suíça.

O diálogo sobre a produção científica requer a criação de espaços de discussão nacional e internacional que coloquem no centro da prática de conhecimento, experiências que permitam refletir sobre as necessidades em saúde, o lugar das políticas públicas e as perspectivas de análises em diferentes contextos. Apresentamos o artigo Problématiques des Centres socio-éducatifs malgachescas: des centres socio-éducatifs à Antananarivo ville et ses périphéries, na República de Madagascar, África, de autoria de Isabelle Odette Rafidimalala, antropóloga e Diretora Geral do Institut Supérieur de Travail Social da Université d'Antananarivo Madagascar. No artigo a autora apresenta o resultado de seus estudos sobre o direito à educação e o papel dos centros socioeducativos, instituições filantrópicas que realizam trabalho com crianças em situação de vulnerabilidade social, especialmente aquelas que já estão fora da escola ou em situação de abandono escolar.

No que tange à Educação e a sua interface com o campo da saúde as autoras Brunella Poltronieri Miguez, Silvia Moreira Trugilho, Hiran Pinel e Solange Rodrigues da Costa Nascimento apresentam o artigo Classe hospitalar e o direito à educação da criança hospitalizada e as autoras Meirielle Soares de Menezes e Ingrid Bezerra Costa Maia apresentam uma interessante discussão sobre a questão da Participação da família no processo de cuidado da criança hospitalizada.

Ainda sobre a temática da infância e juventude o exemplar apresenta artigos sobre Violência intrafamiliar na Infância e Adolescência a percepção dos profissionais de saúde residentes na formação em serviço de autoria de Gessica dos Santos Machado Lopes, Alzira Maria Baptista Lewgoy e Myriam Fonte Marques e também com o artigo Racismo estrutural e institucional e a justiça da infância e juventude: a (des)proteção de crianças e adolescentes negros/as pobres de autoria de Adeildo Vila Nova, Bárbara Canela Marques, Eunice Teresinha Fávero, Gracielle Feitosa de Loiola e Hílkia Maria de Carvalho Dantas, os autores discutem a questão do racismo estrutural e institucional enquanto marcador das relações sociais, refletindo no trato das questões relacionadas à infância e juventude no Brasil na sua 


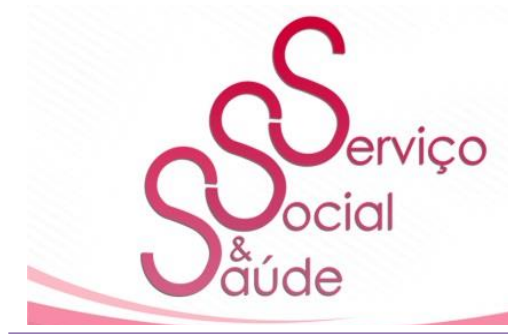

ISSN 2446-5992

(๑⿻)

10.20396/sss.v19i0.8665482

interlocução com o Sistema de Justiça.

No último artigo intitulado Violência contra as mulheres: uma análise sobre a inclusão do conceito de patriarcado nas produções científicas na área da saúde de autoria de Ana Claudia de Oliveira Britto, Cristiane Batista Andrade, Silvana Maria Bitencourt, Aline Azevedo Braga as autoras tecem uma interessante análise sobre violência contra a mulher.

A resenha elaborada por Laína Jennifer Carvalho Araújo apresenta a obra intitulada Serviço Social: formação, pesquisa e trabalho profissional em diferentes contextos organizada por Edna Maria Goulart Joazeiro e Vera Lucia Batista Gomes publicada pela Editora EDUFPI no ano de 2020, fruto da proposta construída no Colóquio de Pós-Graduação em Serviço Social realizado na Oficina Regional Norte da Associação Brasileira de Ensino e Pesquisa em Serviço Social (ABEPSS), em novembro de 2019, na cidade de Belém, Pará. Na resenha a autora apresenta a relevância da obra em virtude das importantes perspectivas de análise sobre a produção de conhecimento do Serviço Social brasileiro, Latino-americano, da Europa Ocidental e da África, no âmbito da Graduação, da Pós-Graduação e do trabalho profissional que fazem parte dessa publicação.

As autoras Hélia Bracons e Fernanda Ferreira apresentam o livro Cuidados paliativos Conheça-os melhor de autoria de Isabel Galriça Neto, publicado pela Editora Francisco Manoel dos Santos, Lisboa, Portugal, no ano de 2020. As autoras destacam que essa produção contribui com uma análise sobre cuidados paliativos em Portugal e sobre sua importância para a população usuária concernida a estes serviços.

Nessa perspectiva, convidamos os leitores, profissionais, pesquisadores, estudantes de graduação e de pós-graduação e o público em geral para refletir sobre os aspectos estruturais e conjunturais que na atualidade se correlacionam e colocam em risco o direito à vida e a cidadania para grandes segmentos da população que estão submetidos aos ditames de necessidades múltiplas. Esperamos que esse encontro permita a abertura de diálogos com vistas a aprofundar a discussão e que contribua para a emergência de novas perspectivas de análises em consonâncias com os desafios desse tempo e do futuro que há de vir. 


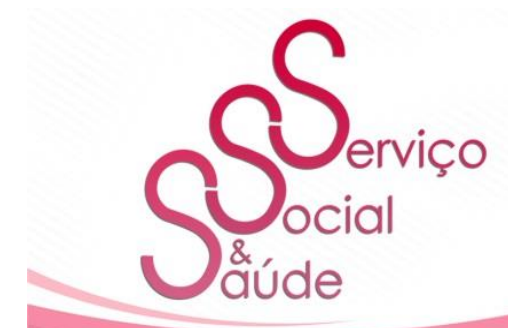

ISSN 2446-5992

(C) 100

10.20396/sss.v19i0.8665482

Campinas (SP), dezembro de 2020.

\section{REFERÊNCIAS}

CHESNAIS, F. As raízes da crise econômica mundial. O Olho da História, Salvador (BA), n. 18, jul. de 2013.

ELIAS, N. Sobre o tempo. Rio de Janeiro: Zahar, 1998.

FRIGOTTO, G. Empresários mais ricos do Brasil: a ignorância, o cinismo e a ganância que matam. Espaço e Economia [Online], v. 17, 2020.

IANNI, O. Enigmas da modernidade-mundo. $3^{\mathrm{a}}$ e. Rio de Janeiro: Civilização Brasileira, 2003.

PEREIRA. P. A. P. A intersetorialidade das políticas sociais na perspectiva dialética In. MONNERAT, G. L; ALMEIDA, N. L. T.; SOUZA, R. G. A intersetorialidade na agenda das políticas sociais. Campinas (SP): Papel Social, 2014, p. 21-40.

PIRES, R. R. C. Os Efeitos sobre grupos sociais e territórios vulnerabilizados das medidas de enfrentamento à crise sanitária da Covid-19: propostas para o aperfeiçoamento da ação pública. Repositório do Conhecimento do IPEA. 2020. 